\title{
Differences in IP-10, TLR4 and IRF5/3 between SVR and non-SVR HCV-1 patients treated with PEG-IFN and ribavirin
}

\author{
MIN ZHANG, YONGFANG JIANG, XINQIANG XIAO, MILIN PENG, FENG PENG and GUOZHONG GONG \\ Institute of Hepatology and Department of Infectious Diseases, \\ The Second Xiangya Hospital, Central South University, Changsha, Hunan 410011, P.R. China
}

Received November 4, 2015; Accepted November 1, 2016

DOI: $10.3892 / \mathrm{mmr} .2017 .6229$

\begin{abstract}
The present study aimed to investigate alterations in Toll-like receptor 4 (TLR4), interferon regulatory factor 5 (IRF5) and interferon- $\gamma$-inducible protein-10 (IP-10), and evaluate whether these factors may be associated with a sustained virological response (SVR) among patients with hepatitis $\mathrm{C}$ virus genotype-1 (HCV-1) who were treated with peginterferon plus ribavirin (PEG-IFN-RBV). A total of 31 Chinese patients infected with $\mathrm{HCV}-1$ were enrolled in the present study and 25 patients obtained SVR. The expression levels of IP-10 declined significantly during PEG-IFN-RBV therapy at the 24 and 48 week time-points, compared with the baseline $(\mathrm{P}<0.005,0.001$ and 0.001 , respectively). In addition, it was observed that IRF5 mRNA expression and the number of $\mathrm{TLR}^{+}$peripheral blood mononuclear cells exhibited similar correlations with IP-10 concentration $\left(\mathrm{R}^{2}=0.0726\right.$, $\mathrm{P}=0.001, \mathrm{R} 2=0.1634, \mathrm{P}<0.0001$, respectively) in the SVR group patients; however, these correlations were not observed to be present in the non-SVR group patients. In conclusion, the results of the present study suggest that marked alterations in IP-10, TLR4 and IRF5 expression may serve as indicators for the development of SVR in patients with HCV-1 treated with PEG-IFN-RBV.
\end{abstract}

\section{Introduction}

The standard treatment for chronic hepatitis $\mathrm{C}$ virus (HCV) infection is a weekly administration of peginterferon (PEG-IFN) combined with a daily dose of ribavirin (RBV). However, $<50 \%$ of patients infected with HCV genotype-1 (HCV-1) treated with this regimen achieve a sustained virological response $(\mathrm{SVR})$ in Western countries $(1,2)$. Treatment

Correspondence to: Professor Guozhong Gong, Institute of Hepatology and Department of Infectious Diseases, The Second Xiangya Hospital, Central South University, 139 People's Road, Changsha, Hunan 410011, P.R. China

E-mail: guozhonggong@yahoo.com

Key words: chronic hepatitis C, interferon- $\gamma$-inducible protein-10, Toll-like receptor 4, interferon regulatory factor 5, sustained virological response with PEG-interferon (IFN) plus RBV activates the immune system, marked by the expression of cell membrane proteins and secretion of cytokines. In a preliminary experiment, the authors of the present study demonstrated that Toll-like receptor 4 (TLR4) expression was significantly downregulated on peripheral blood mononuclear cells (PBMCs) during PEG-IFN and RBV combination therapy in patients with genotype-1 chronic hepatitis $\mathrm{C}$ (CHC) (3). The results suggested that IFN may regulate TLR4 expression, subsequently affecting the immune cell signaling pathways, and thus the production and secretion of cytokines. The TLR transmembrane receptor family is important in the recognition of pathogen-associated molecular patterns, thus leading to the vigorous production of type I IFNs and proinflammatory cytokines (4). It has previously been demonstrated that TLR4 may be induced by hepatocyte-specific transgenic expression of the HCV nonstructural protein (NS)5A (5). TLR4 agonists, including lipopolysaccharide (LPS), have been reported to induce interferon- $\gamma$-inducible protein-10 (IP-10) production (6). Sahin et al (7) described a novel proapoptotic effect of IP-10 in hepatocytes. Notably, the effect is not mediated via its cognate chemokine receptor, but via TLR4. IP-10 is a T-cell-specific CXC chemokine of 77 amino acids in its mature form, which targets $\mathrm{C}-\mathrm{X}-\mathrm{C}$ motif receptor 3 , and attracts natural killer cells, $\mathrm{T}$ lymphocytes and monocytes.

The association between the dynamic alterations of IP-10 during PEG-IFN and RBV treatment of patients with $\mathrm{HCV}-1$, TLR4 expression on PBMCs and the development of the SVR, remains to be fully elucidated. The present study investigated marked alterations in IP-10, TLR4, IRF3 and IRF5 in patients with HCV treated with PEG-IFN-based standard therapy. The results suggested that decreasing levels of IP-10 were observed via a decrease in the expression of TLR4 on PBMCs during PEG-IFN treatment. In addition, SVR may be associated with IP-10, IRF5 and TLR4 expression on PBMCs in patients with $\mathrm{CHC}$ during antiviral therapy.

\section{Materials and methods}

Patients. The present study recruited 31 patients with $\mathrm{CHC} ; 19$ male, and 12 female, who were receiving treatment at the Second Xiangya Hospital of Central South University (Changsha, China) between September 2011 and September 2012. The average age was 39 (range, 33-48 years). 
The HCV RNA load ( $\lg 10$ RNA) was -6.53 (range, -5.95 to -7.20). Alanine transaminase (ALT) and aspartate aminotransferase (AST) levels were: $69.9 \mathrm{IU} / 1$ (range, 39.5-95.5 IU/1) and 57.2 IU/1 (range, 38.0-91.3 IU/1), respectively. CHC was diagnosed according to the Strategy for Prevention and Therapy of Viral Hepatitis (8). HCV was confirmed to be HCV-1 based on genotyping results. All subjects were negative for hepatitis B and D, human immunodeficiency virus, and for other markers of autoimmune hepatitis and drug-induced hepatitis. The present study was approved by the Ethics Committee of the Second Xiangya Hospital (Changsha, China).

Study design. CHC participants received subcutaneous injections of PEG-IFN-a-2a (180 $\mu \mathrm{g}$ /week), and daily oral RBV (15 mg/kg; Kangmei Pharmaceutical Co., Ltd., Shanghai, China) for 48 weeks. Blood samples were collected at the baseline (prior to the treatment) and at 4, 12, 24 and 48 weeks during the treatment, and additionally 24 weeks (72 weeks total) following discontinuation of antiviral treatment.

Virological evaluations. HCV RNA levels were measured using the COBAS TaqMan HCV assay (Roche Molecular Diagnostics, Pleasanton, CA, USA) according to manufacturer's protocols, with low and high cut-off limits of quantification, 15 to $6.9 \times 107 \mathrm{IU} / \mathrm{ml}(1.2-7.8 \mathrm{log} \mathrm{IU} / \mathrm{ml})$. HCV genotype was determined using a HCV Genotype Primer kit (Institute of Immunology, Tokyo, Japan) according to the manufacturer's protocol.

Detection of $T L R 4^{+}$PBMCs. PBMCs were isolated from heparinized blood using Ficoll-Hypaque (Sigma-Aldrich; Merck Millipore, Darmstadt, Germany) density gradient centrifugation in $200 \mu \mathrm{l}$ staining buffer (BD Biosciences, Franklin Lakes, NJ, USA) at room temperature for $5 \mathrm{~min}$ at $800 \mathrm{x} \mathrm{g}$. PBMCs $\left(1 \times 10^{6}\right)$ were incubated with allophycocyanin-labeled anti-TLR4 (1:20; cat. no. 564401; BD Biosciences) in a $100 \mu \mathrm{l}$ experimental sample at room temperature for $30 \mathrm{~min}$, and washed twice prior to analysis with flow cytometry (FACScan flow cytometer; Beckman Coulter, Inc., Brea, CA, USA), using Cell Quest software (version 5.1; BD Biosciences).

RNA isolation and reverse transcription-quantitative polymerase chain reaction (RT-qPCR). Total RNA was extracted from PBMCs using RNeasy Mini kit (Qiagen GmbH, Hilden, Germany). RT-qPCR was conducted using a Rotor-Gene 3000 real-time PCR instrument (Qiagen $\mathrm{GmbH}$ ). RT was conducted with $10 \mu \mathrm{l}$ RNA with $2 \mu \mathrm{l}$ RT primer and amplification kit (Enhanced Avian HS RT-PCR Kit; Sigma-Aldrich; Merck Millipore) at $50^{\circ} \mathrm{C}$ for $60 \mathrm{~min}$ according to the manufacturer's protocol. IRF3 and IRF5 mRNA was amplified with SYBR ${ }^{\circledR}$ real-time PCR kit (Takara Biotechnology Co., Ltd., Dalian, China) using PCR primers presented in Table I. The thermocycling conditions of the reaction were as follows: Initial denaturation at $94^{\circ} \mathrm{C}$ for $3 \mathrm{~min}, 30$ cycles of denaturation at $94^{\circ} \mathrm{C}$ for $30 \mathrm{sec}$, annealing at $58^{\circ} \mathrm{C}$ for $30 \mathrm{sec}$ and elongation at $72^{\circ} \mathrm{C}$ for $30 \mathrm{sec}$, and final elongation at $72^{\circ} \mathrm{C}$ for $7 \mathrm{~min}$. All reactions were conducted in triplicate for three independent experiments. The mean quantification cycle $(\mathrm{Cq})$ value of target genes was normalized against the $\mathrm{Cq}$ value of $\beta$-actin mRNA, and the relative expression levels were calculated
Table I. Polymerase chain reaction primers for IRF3, IRF5 and $\beta$-actin.

\begin{tabular}{lll}
\hline & \multicolumn{1}{c}{ Sequence (5'-3') } & $\begin{array}{l}\text { Size } \\
\text { (bp) }\end{array}$ \\
\hline IRF3 & F: 5'-AAAGAAGGGTTGCGTTTAGC-3' & 161 \\
& R: 5'-CAGAATGTCTTCCTGGGTATCA-3' & \\
IRF5 & F: 5'-GAGCAGGTGGAACTCTTCG-3' & 169 \\
& R: 5'-CACAGGCGGATGGCATAA-3' & \\
\multirow{3}{*}{-actin } & F: 5'-ATCATGTTTGAGACCTTCAACA-3' & 318 \\
& R: 5'-CATCTCTTGCTCGAAGTCCA-3' & \\
\hline
\end{tabular}

IRF $3 / 5$, interferon regulatory factor 3/5; F, forward; R, reverse.

using the following formula: $2^{-\Delta \Delta \mathrm{Cq}}$, where $\Delta \Delta \mathrm{Cq}=\left(\mathrm{Cq}-\mathrm{Cq}_{\beta \text {-actin }}\right)$ CHC patient $-\left(\mathrm{Cq}-\mathrm{Cq}_{\beta \text {-actin }}\right)_{\text {Normal control }}(9)$.

Detection of IP-10 by ELISA. Plasma IP-10 levels were measured using Human CXCL10/IP-10 Quantikine ELISA kit (R\&D Systems, Inc., Minneapolis, MN, USA).

Statistical analysis. All variables were normally distributed, and data was presented as mean \pm standard deviation. Data in multiple groups were compared with one-way analysis of variance followed by Tukey's test, and the comparison between two groups was performed with an independent sample t-test. A paired sample t-test was used to analyze the data of different time points for one group. Spearman correlation analysis was used to analyze the correlation between IP-10 and IRF5, IP-10 and TLR4, and IRF5 and TLR4 in the SVR and non-SVR groups. Multivariate regression analysis was used to analyze the correlation between multiple factors including SVR, IP-10, TLR4 and IRF5. All statistical analyses were based on two-sided hypothesis tests, and $\mathrm{P}<0.05$ was considered to indicate a statistically significant difference. All analyses were carried out using SPSS software version 16.0 (SPSS, Inc., Chicago, IL, USA).

\section{Results}

Baseline characteristics associated with SVR. At baseline, age and gender were comparable between the SVR and non-SVR groups. ALT and AST were significantly higher in the non-SVR group $(\mathrm{P}=0.0032$ and 0.0042 vs. SVR group, respectively). Frequency of TLR4 expression on PBMCs, and levels of serum IP-10, IRF3 and IRF5 were similar between the SVR and the non-SVR groups (Table II).

Viral load and serological alterations in patients with CHC. A total of 25 patients $(80.65 \%)$ achieved SVR and the remaining six did not. HCV-RNA, ALT and AST levels declined gradually during the treatment and follow-up period in the SVR and non-SVR groups. The number of patients with detectable HCV-RNA in the SVR group was significantly fewer than in the non-SVR group at 4,12 and 48 weeks during the treatment period, and the 24 week follow-up ( $P<0.05$; Fig. 1$)$. The percentage of patients with abnormal ALT and AST in the 
Table II. Baseline characteristics in responders vs. non-responders.

\begin{tabular}{lccc}
\hline Characteristic & SVR (n=25) & Non-SVR (n=6) & P-value \\
\hline Age in years median (IQR) & $40(33-46)$ & $47(33-55)$ & 0.687 \\
Gender, male (\%) & 60 & 83 & 0.116 \\
HCV RNA Log 10, median (IQR) & $6.21(2.14-7.05)$ & $6.94(5.95-7.59)$ & 0.558 \\
ALT (IU/l), median (IQR) & $58(37-86.1)$ & $123.7(84.3-219.2)$ & 0.0032 \\
AST (IU/l), median (IQR) & $56(54-98.1)$ & $128.6(75.3-186.5)$ & 0.0042 \\
TLR4-positive PBMCs (\%), median (IQR) & $31.65(27.45-41.89)$ & $45.62(36.73-59.28)$ & 0.0542 \\
IP-10 (pg/ml), median (IQR) & $130.58(119.67-217.59)$ & $186.09(125.69-251.9)$ & 0.0898 \\
IRF3 (RQ), median (IQR) & $14.65(7.45-21.57)$ & $15.62(8.73-29.28)$ & 0.762 \\
IRF5 (RQ), median (IQR) & $20.16(11.59-36.19)$ & $23.59(16.73-39.28)$ & 0.642 \\
\hline
\end{tabular}

IQR, interquartile range; ALT, alanine transaminase; AST, aspartate aminotransferase; HCV, hepatitis C; SVR, sustained virological response, TLR 4, toll-like receptor 4; IRF 3/5 interferon regulatory factor 3/5; IP-10, interferon- $\gamma$-inducible protein-10; RQ, relative quantification.

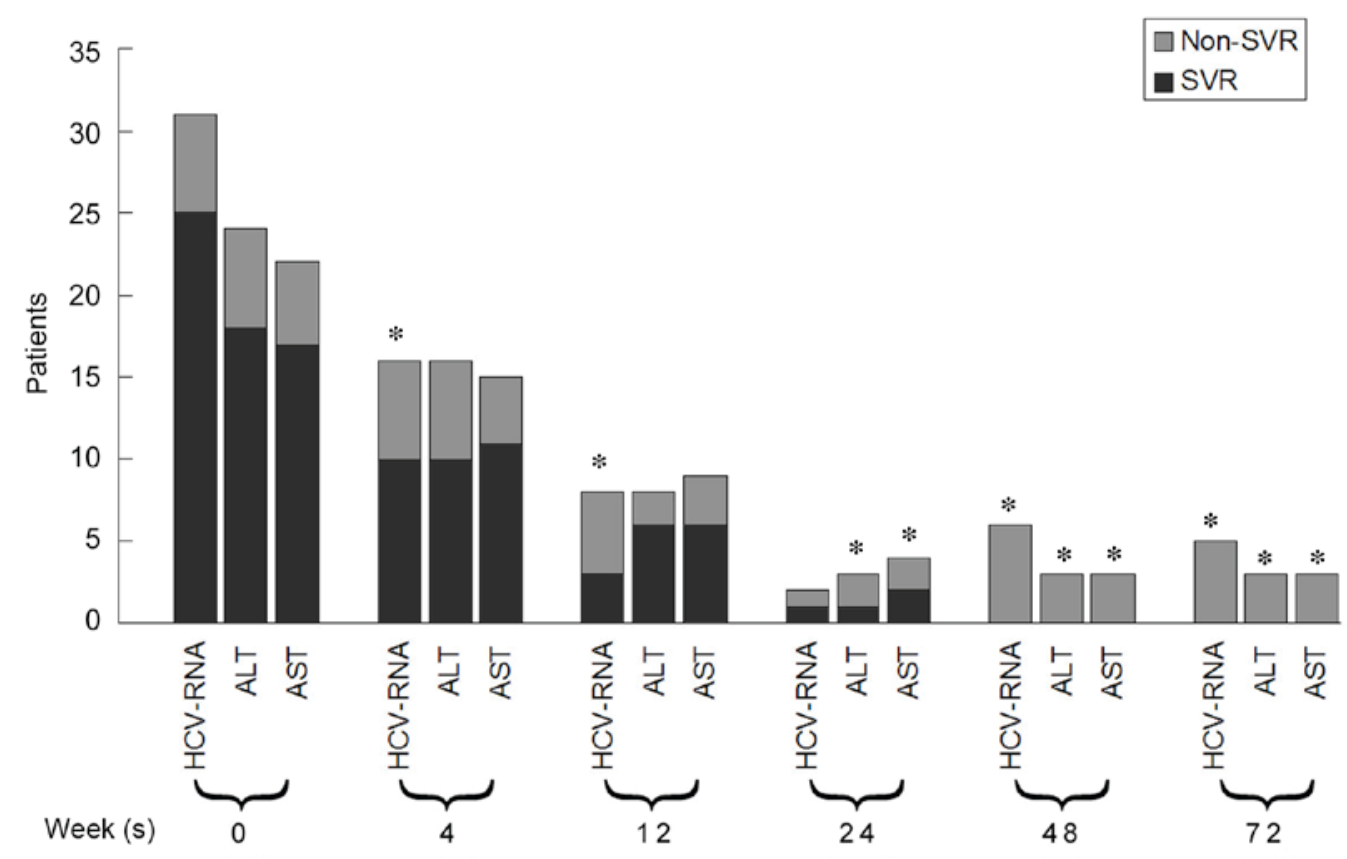

Figure 1. ALT, AST and detectable HCV-RNA variations present in patients in each group at all time points. ${ }^{*} \mathrm{P}<0.05$ vs. the non-SVR group. ALT, alanine transaminase; AST, aspartate aminotransferase; $\mathrm{HCV}$, hepatitis $\mathrm{C}$ virus; $\mathrm{CHC}$, chronic $\mathrm{HCV}$; SVR, sustained virological response.

SVR group at 24 and 48 weeks during the treatment period, and the 24 week follow-up was significantly lower than that in the non-SVR group ( $\mathrm{P}<0.05$; Fig. 1).

TLR4, IRF3, IRF5 and IP-10 alterations between SVR and non-SVR groups, at different time points. There was no difference in the percentage of TRL4 ${ }^{+}$PBMCs in SVR and non-SVR groups at baseline; however, with treatment, the percentage gradually decreased, and was significantly lower at 24 and 48 weeks in the SVR group compared with the non-SVR group $(\mathrm{P}<0.0001$ and $\mathrm{P}<0.0001$; Fig. 2A). The mRNA expression levels of IRF3 were similar at baseline in the SVR and the non-SVR groups [SVR IRF3 relative quantification $(R Q)=22.07 \pm 5.63$ vs. non-SVR IRF3 RQ=24.83 \pm 6.38$]$. With an extended period of treatment the IRF3 RQ values in the SVR group were slightly lower than in the non-SVR group, but there was no statistically significant difference between the two groups. A total of 24 weeks following treatment (72 weeks), the IRF3 RQ values in the non-SVR group were markedly increased compared with the SVR group $(\mathrm{P}=0.035$; Fig. 2B).

Conversely, the IRF5 levels in the SVR group decreased during treatment compared with those of the non-SVR group, even though similar levels were observed at baseline between the two groups (SVR IRF5 RQ=24.52 \pm 13.78 vs. non-SVR IRF5 RQ=21.82 \pm 6.59 ). The IRF5 levels in the SVR group were significantly lower than those in the non-SVR group at times ranging between 24 and 48 weeks following the 


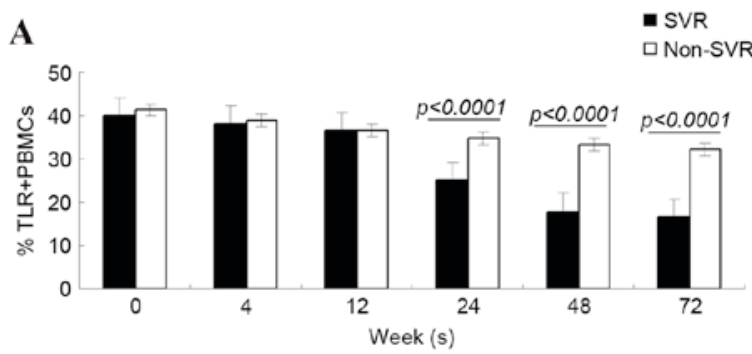

B

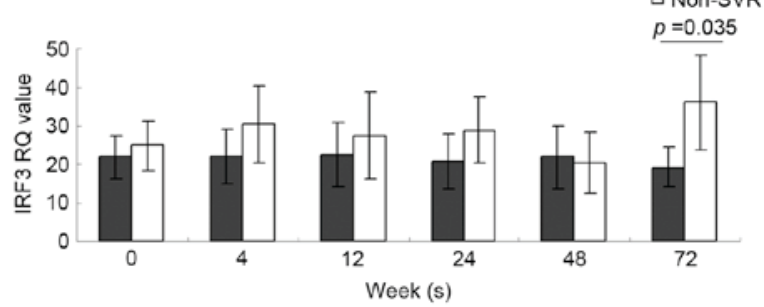

C

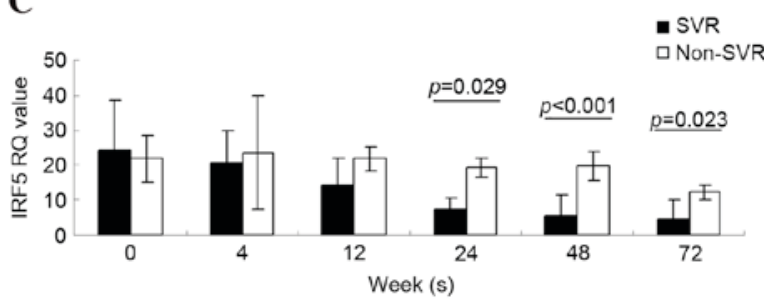

D

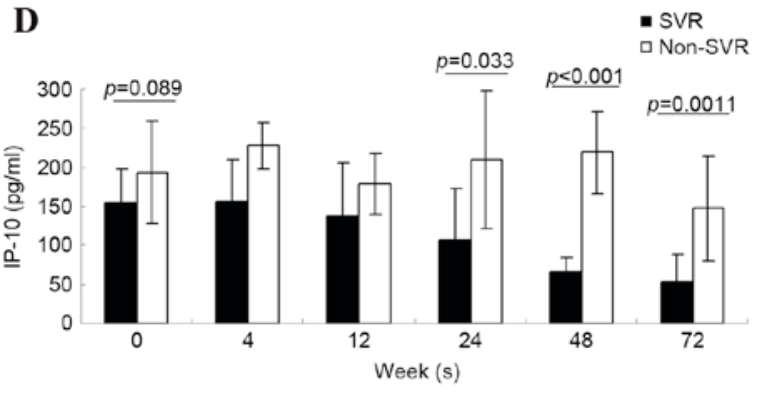

Figure 2. Alterations in TLR4, IRF3, IRF5 and IP-10, and differences between the SVR and non-SVR groups 0-72 weeks following start of therapy. Representation of (A) percentage of TLR4 ${ }^{+}$PBMCs, (B) IRF3 value (C) IRF5 value and (D) IP-10 concentration, over the differing time-points of treatment up to 72 weeks, in SVR and non-SVR groups. Data are presented as the mean \pm standard deviation. TLR4, Toll-like receptor 4; IRF3/5, interferon regulatory factor $3 / 5$; IP-10, interferon- $\gamma$-inducible protein-10; SVR, sustained virological response; PBMCs, peripheral blood mononuclear cells; RQ, relative quantification.

initiation of treatment, and 24 weeks following treatment (SVR IRF5 RQ=7.24 $\pm 3.14,5.66 \pm 1.67,4.62 \pm 1.58$ vs. non-SVR IRF5 $R Q=19.19 \pm 2.75,19.80 \pm 4.25,12.20 \pm 2.00, P=0.029, P<0.001$ and $\mathrm{P}=0.0023$; Fig. 2C).

The baseline levels of IP-10 in the SVR and non-SVR groups were $154.59 \pm 43.36$ and $192.78 \pm 65.25 \mathrm{pg} / \mathrm{ml}$, respectively. There was no statistically significant difference between the two groups $(\mathrm{P}=0.089)$. During the course of treatment, the IP-10 levels in the SVR group decreased. In addition, IP-10 levels did not declined in the non-SVR group. At 24-72 weeks, the IP-10 levels in the SVR group were significantly lower than in the non-SVR group. The IP-10 expression levels at the final three time points $(24,48$ and 72 weeks) were $107.71 \pm 65.74,64.89 \pm 20.19$ and $52.77 \pm 35.1 \mathrm{ng} / \mathrm{ml}$, respectively
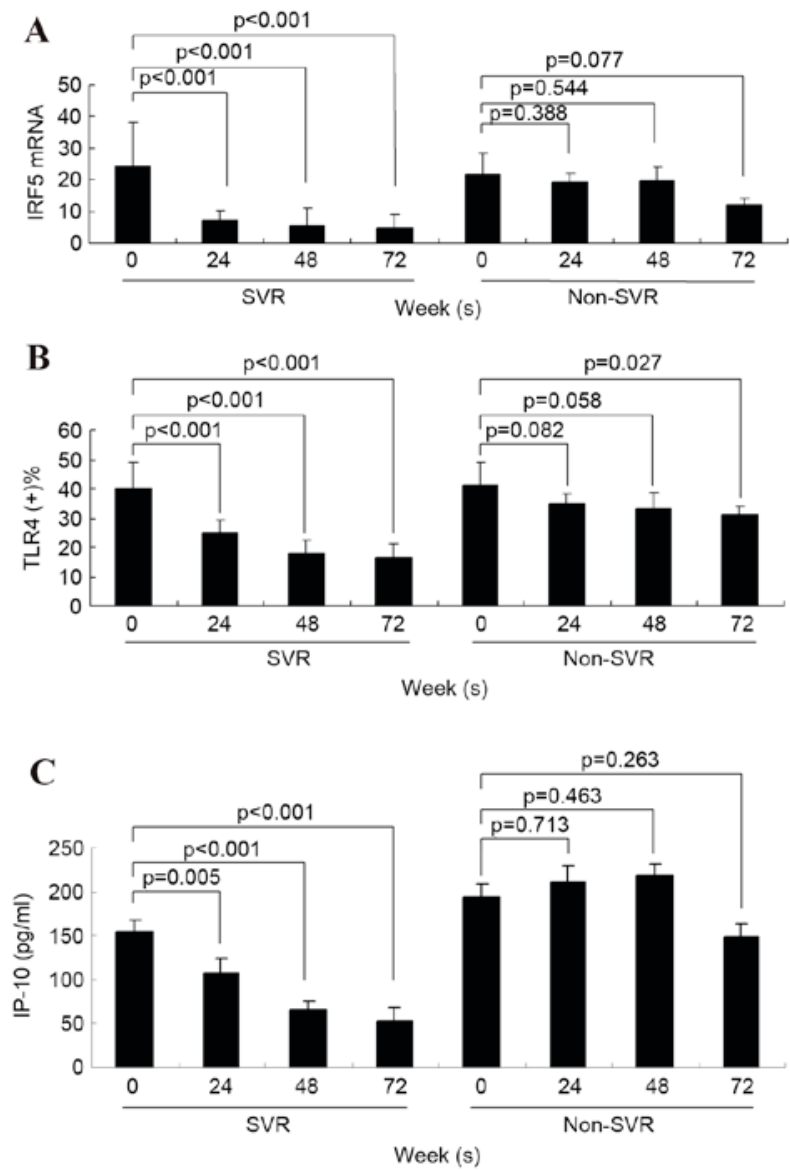

Figure 3. Comparison of (A) IRF5 mRNA, (B) TLR4 ${ }^{+} \%$, and (C) IP-10 concentration levels at different time points in the SVR/non-SVR groups. Data are presented as the mean \pm standard deviation. TLR4, Toll-like receptor 4; IRF3/5, interferon regulatory factor $3 / 5$; IP-10, interferon- $\gamma$-inducible protein-10; SVR, sustained virological response.

in the SVR group vs. 209.85 $\pm 88.87,218.88 \pm 112.67$, and $147.65 \pm 66.68 \mathrm{pg} / \mathrm{ml}$ in the non-SVR group. $\mathrm{P}=0.003, \mathrm{P}<0.001$ and $\mathrm{P}=0.0011$; Fig. 2D).

Decrease of serum IP-10 in SVR. Within the SVR group, serum IRF5 mRNA expression, serum IP-10 concentration and the percentage of TLR4 ${ }^{+}$PBMCs were all significantly lower at 24, 48 and 72 weeks compared with the pretreatment baseline. In the non-SVR group, a significant decrease in serum IP-10 concentration was not detected following treatment (Fig. 3).

Correlations between serum levels of IP-10, TLR4 and IRF5. Serum IP-10 levels exhibited a positive correlation with IRF5 RQ values and with the frequency of TLR4 ${ }^{+}$PBMCs in the SVR group, $\left(\mathrm{R}^{2}=0.0726, \mathrm{P}=0.001, \mathrm{R}^{2}=0.1634, \mathrm{P}<0.0001\right.$, respectively) but not in the non-SVR group (Fig. 4). In addition, a positive correlation was observed between IRF5 and the frequency of TLR4 ${ }^{+}$PBMC cells in the SVR group (Fig. 4).

\section{Discussion}

HCV infects 130-170 million people worldwide and frequently leads to the development of cirrhosis and hepatocellular carcinoma (HCC) (1). The incidence of HCV in China is 
A

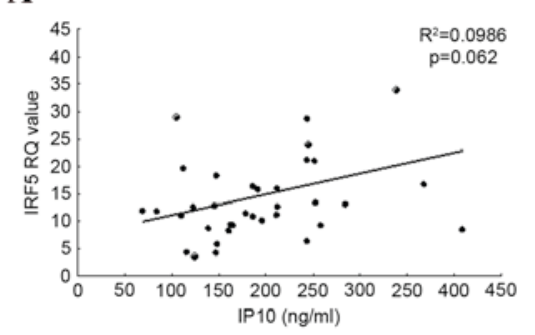

D

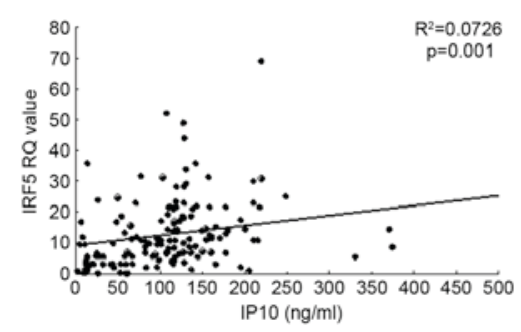

B

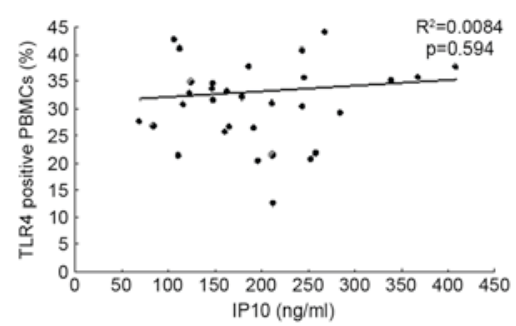

$\mathbf{E}$

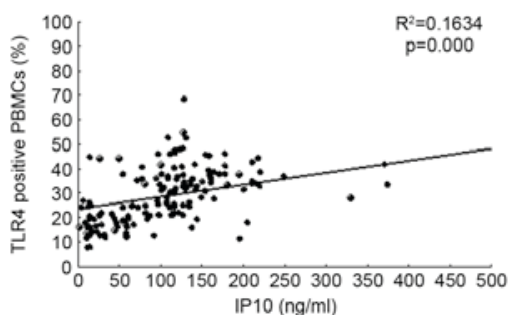

C

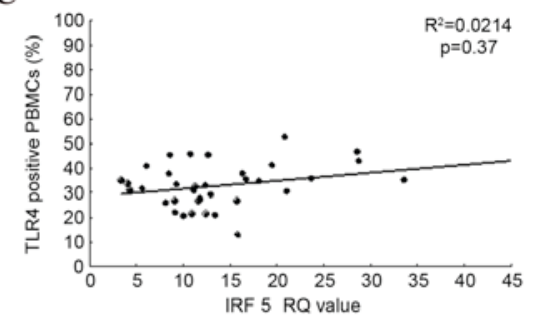

$\mathbf{F}$

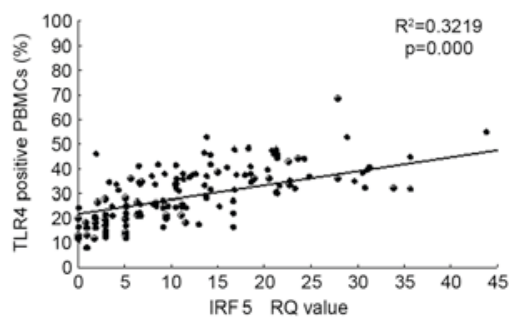

Figure 4. IP-10, TLR4 and IRF5 serum level correlations. There was no positive correlation observed between (A) IP-10 and IRF5, (B) IP-10 and TLR4+ ${ }^{+}$or (C) IRF5 and TLR4+ levels in the non-SVR group. A positive correlation was observed between (D) IP-10 and IRF5, (E) IP-10 and TLR4 ${ }^{+}$and (F) IRF5 and $\mathrm{TLR}^{+}$levels in the SVR group. Data are presented as the mean \pm standard deviation. TLR4, Toll-like receptor 4; IRF3/5, interferon regulatory factor 3/5; IP-10, interferon- $\gamma$-inducible protein-10; SVR, sustained virological response; RQ, relative quantification.

high: 42 million people are infected, with an infection rate of $2.6 \%$ (10). Spontaneous viral clearance occurs in some patients following acute HCV infection; however, $50-80 \%$ of individuals with an acute $\mathrm{HCV}$ infection have it develop into a chronic infection, and are at a significant risk of progressive liver fibrosis, and subsequent liver cirrhosis and HCC.

Cytotoxic T cell (CTL) depletion or impairment is one of the major features of chronic HCV infection. CTLs exhibit a decline in the secretion of antiviral cytokines and proliferative capacity, leading to a decrease in cytotoxicity $(11,12)$. T-cell activation is triggered primarily via major histocompatibility complex molecules loaded with viral peptides on antigen-presenting cells (APCs). There are two signaling events involved in the activation process: Signal 1 is provided by the T-cell receptor and signal 2 by co-stimulatory signals, predominantly via cluster of differentiation (CD) 28, which interacts with its ligands on the surface of APCs: B7-1 (CD80) and B7-2 (CD86) (13). These co-stimulatory molecules provide an activating signal, whereas others provide an inhibitory signal and the balance between the two determines the outcome of the cellular immune response (14). TLRs are a class of innate immune receptors that may be expressed on APCs and immune effector cells. TLR signals are transduced via two main pathways: Myeloid differentiation primary response 88 (MyD88)-dependent and MyD88-independent signaling pathways. These two pathways result in the activation of mitogen-activated activated protein kinases (MAPKs) and transcription factors that regulate inflammation, including nuclear factor- $\kappa \mathrm{B}$, which regulates the production of IFN- $\beta$, which in turn induces an increase in the levels of co-stimulatory molecules, such as CD80 (B7-1) and CD86 (B7-2) on the surface of APCs, and signals other cells to secrete cytokines including IL-1, IL-6, IL-8, IL-12 and tumor necrosis factor (TNF)- $\alpha$, which all contribute to the activation of the adaptive immune response (4).
TLR4 is a transmembrane receptor that recognizes LPS as its primary ligand (15). The function of TLR4 in LPS-stimulated proinflammatory responses of Kupffer cells has been well characterized $(16,17)$, and a previous study has suggested a direct role of TLR4 in hepatic fibrogenesis (18). Results from in vitro experiments indicated that TLR4 may have a close association with sustained HCV infection. TLR4 was upregulated in BV2 cells incubated with HCV-positive serum, leading to the secretion of the inflammatory cytokine TNF- $\alpha$ (19). Transfection of QSG7701 cells with pCN5A; an NS5A expression vector, led to a detection of HCV NS5A in the cytoplasm, and an upregulation of the mRNA and protein expression levels of TLR4 (20). Activation of TLR4 results in inflammation by promoting the secretion of inflammatory cytokines, such as TNF- $\alpha$ and IL-6, via the MyD88-dependent pathway; and antiviral effects by promotion of the secretion of IFN- $\beta$ via the MyD88-independent pathway (21). A previous study has also demonstrated that the increased plasma levels of IP-10 in hyperglycemia are mediated by the TLR4 pathway (22).

PEG-TNF- $\alpha 2 \mathrm{a}$ is now widely regarded as one of the most effective antiviral drugs for the treatment of CHC. It inhibits the replication of HCV RNA in cells, whilst modulating the immune functions to promote removal of the virus. Genotype-1 virus is associated with refractory $\mathrm{HCV}$ and several patients infected with this genotype fail to achieve an ideal response to antiviral therapy. Therefore, it is important to establish a curative effect prediction index prior to and during the process of treatment to improve patient compliance, to have an expectation of the long-term efficacy of treatment and promptly adjust the treatment plan. The current study investigated the marked alterations in TLR4 expression, IRF3, IRF5 and IP-10 levels in PBMCs of patients with chronic HCV treated with PEG-IFN plus RBV, and the possible correlation among these factors. To establish the association between these factors 
and the efficacy of IFN therapy, the present study observed 31 cases of patients with CHC treated with PEG-IFN- $\alpha$ 2a in combination with RBV, and determined the IL-28B genotype, the serum HCV-RNA load, the percentage of TLR4 ${ }^{+}$PBMCs, the mRNA expression levels of IRF3 and IRF5 in PBMCs, and serum IP-10 levels at baseline and 4, 12, 24, 48 and 72 weeks following treatment, and analyzed the association between the curative effects and these factors.

In the cohort of Chinese patients in the present study, $80.65 \%$ (25 cases) exhibited SVR, which is significantly greater compared with the value of $42-52 \%$ of patients in Western countries (1). The remaining six patients $(19.35 \%)$ did not reach SVR. TLR4 expression on PBMCs and levels of serum IP-10, IRF3 and IRF5 at baseline were similar between the SVR and non-SVR groups.

The results of the present study suggested that the success of IFN plus RBV treatment for patients with genotype-1 CHC that exhibit SVR is associated with a reduction in the percentage of TLR4 ${ }^{+}$PBMCs, lower levels of IRF5 mRNA in PBMCs, and a reduction in the levels of inflammatory factors, including IP-10. IP-10 is categorized in the CXC subfamily of chemokines, which contain a single and variable amino acid between the first two of four highly conserved cysteine residues (23). Determination of high levels of IP-10 in bodily fluids is therefore a marker of host immune response, particularly $\mathrm{T}$ helper 1 polarized $\mathrm{T}$ cells (24). It has been suggested that the chemokine IP-10 is important in chronic inflammatory conditions, including various autoimmune diseases (25). Previous studies have suggested a significant association between the expression of the CXC chemokines and the development of progressive liver injury in patients with CHC (26,27). IP-10 is a key factor in liver inflammation, and is expressed in the liver of patients with HCV (28-30). Various independent studies indicated that elevated plasma levels of IP-10 predict the failure of combination therapy $(31,32)$. Human serum levels of IP-10 range between 20 and $400 \mathrm{pg} / \mathrm{ml}$, with the higher values commonly observed among individuals with chronic inflammatory conditions, including HIV infection and HCV (33). To the best of our knowledge, the present study additionally observed for the first time, that a decrease in the serum concentration of IP-10 was associated with SVR, as the difference in IP-10 levels 24-72 weeks following treatment between the SVR and the non-SVR groups was statistically significant. A previous study reported significant differences in pretreatment serum IP-10 concentrations between patients with SVR or those without; however, our study did not replicate these findings (34). The reasons for these discrepancies are unclear, it may due to the smaller sample size. These results revealed that compared with the baseline levels of IP-10, the decline of serum levels of IP-10 throughout the course of treatment is an effective predictor of the occurrence of SVR in IFN plus RBV treatment of HCV-1.

The results of the present study demonstrated that serum IP-10 expression levels were positively correlated with IRF5 mRNA RQ value in PBMCs and with the \% TLR4 ${ }^{+}$PBMCs, $\left(\mathrm{R}^{2}=0.0726, \mathrm{P}=0.001\right.$ and $\mathrm{R}^{2}=0.1634, \mathrm{P}<0.0001$, respectively $)$ in the SVR group, but not in the non-SVR group. The IRF5 mRNA RQ value in PBMCs also correlated with the frequency of TLR4+ PBMCs in the SVR group. Assessments of the associations between serum IP-10 and TLR4, IRF5 and IRF3 revealed that IP-10 concentration was significantly correlated with TLR4 and IRF5 in the SVR group. The correlation between these indicators was not observed in the non-SVR group. TLR4 expression on PBMCs was significantly lower in the SVR group at 24, 48 and 72 weeks into the treatment $(\mathrm{P}<0.0001)$. IRF5 levels in the SVR group were decreased with the extension of treatment time, but this was not observed in the non-SVR group. IRF5 levels in the SVR group were significantly lower compared with the non-SVR group at 24-48 weeks, and 24 weeks following treatment (SVR IRF5 $\mathrm{RQ}=7.24 \pm 3.14,5.66 \pm 1.67,4.62 \pm 1.58$ vs. non-SVR IRF5 $\mathrm{RQ}=19.19 \pm 2.75,19.80 \pm 4.25,12.20 \pm 2.00, \mathrm{P}=0.029, \mathrm{P}<0.001$, $\mathrm{P}=0.023)$. The results suggested that the dynamic changes of IRF5 may have a certain correlation with TLR4 in the SVR group.

In conclusion, the results of the present study demonstrated an association between the decrease in IP-10 levels and a favorable viral kinetic response during combination treatment with PEG-IFN- $\alpha 2 \mathrm{a}$ and RBV in patients infected with HCV-1. A similar association was observed between TLR4 ${ }^{+}$ PBMCs and IRF5 mRNA expression levels. Further studies may include an analysis of the underlying mechanism of how IFN results in a decline of TLR4 expression, which in turn may affect IRF5 signaling pathways and result in a decrease of IP-10, which may exhibit an association with the outcome of antiviral treatment in patients with genotype-1 CHC. The baseline expression levels of TLR4 within PEG-IFN plus RBV-treated patients may be associated with the expression of the IL-28B genotype in the host, resulting in the subsequent development of SVR.

\section{References}

1. Fried MW, Shiffman ML, Reddy KR, Smith C, Marinos G, Gonçales FL Jr, Häussinger D, Diago M, Carosi G, Dhumeaux D, et al: Peginterferon alfa-2a plus ribavirin for chronic hepatitis C virus infection. N Engl J Med 347: 975-982, 2002.

2. Hadziyannis SJ, Sette H Jr, Morgan TR, Balan V, Diago M, Marcellin P, Ramadori G, Bodenheimer H Jr, Bernstein D, Rizzetto M, et al: Peginterferon-alpha2a and ribavirin combination therapy in chronic hepatitis C: A randomized study of treatment duration and ribavirin dose. Ann Intern Med 140: 346-355, 2004

3. Zhang M, Jiang YF, Xiao XQ, Liu SF, Peng ML, Liu D and Gong GZ: Dynamic changes in PD-1, TLR3, and TLR4 surface expression on peripheral blood mononuclear cells in chronic hepatitis $\mathrm{C}$ patients undergoing PEG-IFNalpha-2a plus ribavirin combination therapy. Zhonghua Gan Zang Bing Za Zhi 21: 196-201, 2013 (In Chinese).

4. Akira S, Uematsu S and Takeuchi O: Pathogen recognition and innate immunity. Cell 124: 783-801, 2006.

5. Machida K, Tsukamoto H, Mkrtchyan H, Duan L, Dynnyk A, Liu HM, Asahina K, Govindarajan S, Ray R, Ou JH, et al: Toll-like receptor 4 mediates synergism between alcohol and $\mathrm{HCV}$ in hepatic oncogenesis involving stem cell marker Nanog. Proc Natl Acad Sci USA 106: 1548-1553, 2009.

6. Tedgui A and Mallat Z: Cytokines in atherosclerosis: Pathogenic and regulatory pathways. Physiol Rev 86: 515-581, 2006.

7. Sahin H, Borkham-Kamphorst E, do O NT, Berres ML, Kaldenbach M, Schmitz P, Weiskirchen R, Liedtke C, Streetz KL, Maedler K, et al: Proapoptotic effects of the chemokine, CXCL 10 are mediated by the noncognate receptor TLR4 in hepatocytes. Hepatology 57: 797-805, 2013.

8. Chinese Liver Disease Association; Chinese Infectious and Parasitic Diseases Association: The strategy for prevention and therapy of viral hepatitis C. Chin J Clinic Hepatol 12: 194-198, 2004. 
9. Zeremski M, Dimova R, Brown Q, Jacobson IM, Markatou M and Talal AH: Peripheral CXCR3-associated chemokines as biomarkers of fibrosis in chronic hepatitis $\mathrm{C}$ virus infection. J Infect Dis 200: 1774-1780, 2009.

10. Cui Y and Jia J: Update on epidemiology of hepatitis B and C in China. J Gastroenterol Hepatol 28 (Suppl 1): S7-S10, 2013.

11. Gruener NH, Lechner F, Jung MC, Diepolder H, Gerlach T, Lauer G, Walker B, Sullivan J, Phillips R, Pape GR and Klenerman P: Sustained dysfunction of antiviral CD8+ $\mathrm{T}$ lymphocytes after infection with hepatitis $\mathrm{C}$ virus. J Virol 75: 5550-5558, 2001

12. Wedemeyer H, He XS, Nascimbeni M, Davis AR, Greenberg HB Hoofnagle JH, Liang TJ, Alter $\mathrm{H}$ and Rehermann B: Impaired effector function of hepatitis $\mathrm{C}$ virus2specific CD8+ T cells in chronic hepatitis C virus infection. J Immunol 169: 3447-3458, 2002.

13. Greenwald RJ, Freeman GH and Sharpe AH: The B7 family revisited. Annu Rev Immunol 23: 515-548, 2005.

14. Nurieva R, Thomas S, Nguyen T, Martin-Orozco N, Wang Y, Kaja MK, Yu XZ and Dong C: T-cell tolerance or function is determined by combinatorial costimulatory signals. EMBO J 25 : 2623-2633, 2006.

15. Beutler B: Inferences, questions and possibilities in toll-like receptor signalling. Nature 430: 257-263, 2004.

16. Machida K, Cheng KT, Sung VM, Levine AM, Foung S and Lai MM: Hepatitis C virus induces toll-like receptor 4 expression, leading to enhanced production of beta interferon and interleukin-6. J Virol 80: 866-874, 2006.

17. Dolganiuc A, Norkina O, Kodys K, Catalano D, Bakis G, Marshall C, Mandrekar P and Szabo G: Viral and host factors induce macrophage activation and loss of toll-like receptor tolerance in chronic HCV infection. Gastroenterology 133: 1627-1636, 2007.

18. Guo $J$ and Friedman SL: Toll-like receptor 4 signaling in liver injury and hepatic fibrogenesis. Fibrogenesis Tissue Repair 3: 21, 2010.

19. Liu Q and Wang ZH: The changes of TLR4 expression and TNF-a secretion in BV2 cells after handled with HCV positive serum. Courrent Immunlolgy 31: 219-222, 2011 (In Chinese).

20. Wen M, Xiao XQ and Gong GZ: Hepatitis C virus NS5A protein stimulates TLR4 expression. Chin J Clin Hepatol 27: 49-52, 2011.

21. Andreakos E, Foxwell B and Feldmann M: Is targeting toll-like receptors and their signaling pathway a useful therapeutic approach to modulating cytokine-driven inflammation? Immunol Rev 202: 250-265, 2004.

22. Devaraj S and Jialal I: Increased secretion of IP-10 from monocytes under hyperglycemia is via the TLR2 and TLR4 pathway. Cytokine 47: 6-10, 2009.

23. Mihm S, Schweyer S and Ramadori G: Expression of the chemokine IP-10 correlates with the accumulation of hepatic IFN-gamm a and IL-18mRNA in chronic hepatitis C but not in hepatitis B. J Med Virol 70: 562-570, 2003.
24. Fiorentino DF, Bond MW and Mosmann TR: Two types of mouse T helper cells. IV. Th2 clones secrete a factor that inhibits cytokine production by Th1 clones. J Exp Med 170: 2081-2095, 1989.

25. Antonelli A, Ferrari SM, Giuggioli D, Ferrannini E, Ferri C and Fallahi P: Chemokine (C-X-C motif) ligand (CXCL)10 in autoimmune diseases. Autoimmun Rev 13: 272-280, 2014.

26. Larrubia JR, Benito-Martínez S, Calvino M,Sanz-de-Villalobos E and Parra-Cid T: Role of chemokines and their receptors in viral persistence and liver damage during chronic hepatitis $C$ virus infection. World J Gastroenterol 14: 7149-7159, 2008.

27. Zeremski M, Petrovic LM, Chiriboga L, Brown QB, Yee HT, Kinkhabwala M, Jacobson IM, Dimova R, Markatou M and Talal AH: Intrahepatic levels of CXCR3-associated chemokines correlate with liver inflammation and fibrosis in chronic hepatitis C. Hepatology 48: 1440-1450, 2008.

28. Harvey CE, Post JJ, Palladinetti P, Freeman AJ, Ffrench RA, Kumar RK, Marinos G and Lloyd AR: Expression of the chemokine IP-10 (CXCL10) by hepatocytes in chronic hepatitis C virus infection correlates with histological severity and lobular inflammation. J Leukoc Biol 74: 360-369, 2003.

29. Narumi S, Tominaga Y, Tamaru M, Shimai S, Okumura H, Nishioji K, Itoh Y and Okanoue T: Expression of IFN-inducible protein-10 in chronic hepatitis. J Immunol 158: 5536-5544, 1997.

30. Shields PL, Morland CM, Salmon M, Qin S, Hubscher SG and Adams DH: Chemokine and chemokine receptor interactions provide a mechanism for selective $\mathrm{T}$ cell recruitment to specific liver compartments within hepatitis C-infected liver. J Immunol 163: 6236-6243, 1999.

31. Romero AI, Lagging M, Westin J, Dhillon AP, Dustin LB, Pawlotsky JM, Neumann AU, Ferrari C, Missale G, Haagmans BL, et al: Interferon (IFN)-gamma-inducible protein-10: Association with histological results, viral kinetics, and outcome during treatment with pegylated IFN-alpha $2 \mathrm{a}$ and ribavirin for chronic hepatitis C virus infection. J Infect Dis 194: 895-903, 2006

32. Butera D, Marukian S, Iwamaye AE, Hembrador E, Chambers TJ, Di Bisceglie AM, Charles ED, Talal AH, Jacobson IM, Rice CM and Dustin LB: Plasma chemokine levels correlate with the outcome of antiviral therapy in patients with hepatitis $\mathrm{C}$. Blood 106: 1175-1182, 2005.

33. Diago M, Castellano G, García-Samaniego J, Pérez C, Fernández I, Romero M, Iacono OL and García-Monzón C: Association of pretreatment serum interferon gamma inducible protein 10 levels with sustained virological response to peginterferon plus ribavirin therapy in genotype 1 infected patients with chronic hepatitis C. Gut 55: 374-379, 2006.

34. Darling JM, Aerssens J, Fanning G, McHutchison JG, Goldstein DB, Thompson AJ, Shianna KV, Afdhal NH, Hudson ML, Howell CD, et al: Quantitation of pretreatment serum interferon- $\gamma$-inducible protein-10 improves the predictive value of an IL28B gene polymorphism for hepatitis C treatment response. Hepatology 53: 14-22, 2011. 